\title{
An Experiment in Political Trust
}

\author{
Cortney S. Rodet \\ Florida Southern College
}

\begin{abstract}
March 2015
Trust is foundational in principal-agent relationships. I explore political trust through an experiment in which representative agents can improve their own welfare at the expense of voters. Collective voting and valuable seniority advantage make it difficult to foster accountability for trust betrayal. Subjects participate in a voting game with uncertain payoff redistribution, which allows agents to conceal self-interested behavior. The treatments vary the amount of information to voters compared to a baseline in which they are only aware of their payoff each period. I test to see whether revealing the intentions of the agent spurs a reaction to trust betrayal and whether accountability is comparison dependent. The collective-action problem and value of seniority affect observed accountability, but having a yardstick comparison across agents significantly increases accountability.
\end{abstract}

JEL codes: C91, C92, D03, D72, D89

keywords: voting, experiments, trust, information, seniority, principal-agent 


\section{INTRODUCTION}

Trust between principal and agent - defined as the expectation of the latter acting in the interest of the former - is foundational in political economy, not only from a macro level where trust in the institutional system influences civic engagement, but at the micro level where violations of trust influence voter participation and vote choice (Levi and Stoker 2000). Existing studies have sought to understand political trust using survey based data. This paper addresses trust within the principal-agent relationship between politician and voter in a laboratory experiment where accountability for trust betrayal is uncertain given the collective-action problem and the value of seniority advantage.

I study whether revealing the betrayal of trust spurs greater accountability in the form of a lower likelihood of voting to reelect shirking incumbent politicians, and by extension, a lower likelihood of reelection. The experimental game featured in this paper centers on an incumbent's ability to redistribute resources to his voters. Tension arises due to the uncertainty of the 'quality' of the redistribution, the opportunity for shirking, and the positive effect seniority (measured by relative tenure) has on voters' payoffs. Voters in the baseline only see their payoffs each period, whereas voters in the treatment conditions receive varying amounts of information that distinguish resulting payoffs from the intentions of politicians. Voters in the treatment conditions are either informed of their own incumbent politician's choices or informed of all incumbents' choices each period. This allows us to distinguish the effect of betrayal itself from the consequences of betrayal (i.e. lower payoffs) (Aimone and Houser 2012). Furthermore, expanding feedback to include the behavior of incumbent politicians in other groups permits us to see whether accountability for betrayal is comparison dependent. That is, does the behavior of 
other incumbents serve as a reference for constructing expectations and guide voters in exacting retribution for betrayed trust?

There are two reasons to include seniority in the voting environment. First, uncertain outcomes deteriorate the incumbent's performance signal to voters, so seniority acts to insure incumbents against bad outcomes, which allows for shirking. Second, it transforms the voting decision into an even larger collective decision where not only voters in a particular district must act jointly to enact change, but voters with conflicting interests across various districts must coordinate to effectively respond to violations of trust and change the grander representative apparatus (Buchanan and Congleton 1994; Dick and Lott 1993). In theory, recurring competitive elections and the potential for long-term employment could solve the principal-agent problem, but using tenure as an allocation mechanism for political power (namely benefits) incentivizes the voter to lower her performance standard and transforms the problem of accountability into a large scale collective-action problem of a remarkable nature. Seniority is a key indicator of an incumbent's experience, connections and leadership roles and makes not reelecting the incumbent for violations of trust costly (Bernhardt, Dubey and Hughson 2004; Buchanan and Congleton 1994; Chari et al. 1997; Chen and Niou 2005; Dick and Lott 1993; Friedman and Wittman 1995; Holcombe 1989; Knight 2002; McKelvey and Riezman 1992; Muthoo and Shepsle 2010; Weingast and Marshall 1988). Thus the experiment provides a strong test of trust in a context that complements existing work in two areas: political economy and behavioral economics, where the emphasis has primarily been on individual decision making.

The benefit of an experimental study is the lack of partisan or ideological commitment that affect one's propensity to trust and to respond to betrayal (Finkel et al. 2002, Parker and Parker 1993). It also separates trust in the system from trust in the representative agent, which is 
more difficult to do using survey data. Furthermore, the response of voters in the experiment is limited to one simple action and constrained by the accessible information. Therefore, if trust drives the principal's decision calculus, we can infer that intentions matter as has been shown in other contexts (Falk, Fehr and Fischbacher 2008; McCabe, Rigdon and Smith 2003; Rigdon, McCabe and Smith 2007).

I find that accountability for trust betrayal in terms of voting against the incumbent increases with the amount of information voters receive. Accountability also increases when voters receive information about the actions of incumbents in groups besides their own. For their part, incumbents respond to voters being better informed by being more trustworthy.

Section 2 covers the relevant literature related to this research and further motivates the study while building a case for the hypotheses tested. Section 3 explains the design, and Section 4 includes the results. Section 5 highlights possible policy implications, and Section 6 concludes the paper.

\section{RELEVANT LITERATURE AND HYPOTHESIS DEVELOPMENT}

There is some ambiguity regarding the definition of political trust. One focus in the literature is the moral expectations of how politicians and government should be 'fair, equitable, honest, efficient and responsive to society's needs' (Listhaug 1990 pg 358), while a second notion of political trust blurs the lines between trust and confidence in a political actor's abilities. A third focus is the trustor's expectation of the trustee acting her interest and how distrust affects trustee behavior such as participation and vote choice (Levi and Stoker 2000), which is the central emphasis of this research.

Trust is crucial from an institutional perspective because of its impact on compliance without coercion and commitment to collective action (see Keele 2007 for a review). For 
instance, economists question why people pay taxes given the low probability of detection and punishment. Typical compliance rates imply extreme risk aversion among taxpayers (Alm et al 1992). Feld and Frey (2002) use survey evidence to argue that instead of compliance being a result of risk aversion there exists a psychological contract between tax authorities and tax payers. Higher 'tax morale' implies a higher rate of compliance, but morale is dependent on how tax authorities treat taxpayers.

Levi and Stoker (2000) argue that 'trust judgments' inspire behavioral responses that reflect the beliefs about the trustworthiness of other people. For example, betrayals might 'inspire vigilance in and monitoring of a relationship, uncooperative behavior, or the severing of a relationship' (pg 475). Obvious analogs for voters are election participation and anti-incumbent voting. Sigelman et al. (1992) conducted an experiment where subjects reacted to the actions of a fictitious politician described in vignettes and found that low-trusting subjects were more likely than high-trusting subjects to penalize politicians who disregarded the public's preferences and instead made decisions out of self-interest. Much of the existing work uses surveys to connect trust to vote choice; however, the challenge of inferring causality from survey data is that feelings of distrust among voters may be long lasting and might reflect a general cynicism that biases the evaluation of the current incumbent administration. Nevertheless, survey studies on vote choice are relatively definitive in identifying distrust as a cause for an anti-incumbent response in presidential races, support for third-party contenders, and support for term-limits (Hetherington 1999, Karp 1995, Peterson and Wrighton 1998). Parker (1989), for example, constructed an index of trust using open ended survey questions asking respondents to evaluate their current representative and found that it was a stronger predictor of incumbent evaluation and vote choice than party identification. 
Standard rational choice relies on repeated interaction to explain trust as well as the fulfillment of unenforceable contracts, but economists have also gained insight into trust and betrayal by turning to psychology. Research shows humans to be sensitive to the betrayal of trust and that they are willing to incur costs to exact retribution from the offender (Abbink, Irlenbusch and Renner 2000; Berg, Dickhaut and McCabe 1995; Camerer 2003 and references therein; Finkel et al. 2002; Koehler and Gershoff 2003; Ostrom and Walker 2002). The issue of trust in politics is interesting precisely because of the inherent collective action problem of exacting retribution.

Besley and Case (1995) develop a model incorporating the comparison of incumbent performance across districts - what they call 'yardstick competition.' One of the key experimental treatments in this study allows for yardstick competition by informing voters of all incumbents' decisions including those in other districts. This provides a common measure to which voters can compare shirking. It may induce leniency if a voter's incumbent is shirking much less than other incumbents; likewise, it can induce intolerance even when the incumbent is shirking little in absolute terms but is the only incumbent misbehaving.

Jointly this previous scholarship makes a case for why accountability will increase with transparency and information. This brings us to the first two hypotheses to be tested:

Hypothesis 1: Conditional on the level of shirking, the likelihood of voting for the incumbent and the likelihood of reelection will decrease between treatments as voters are more informed. Hypothesis 2: The likelihood of voting for the incumbent and the likelihood of reelection will decrease within treatments as shirking increases. 
The impact of public information on politician performance has been well documented by political economists (Besley and Burgess 2002; Djankov, McLiesh, Nenova, and Shleifer 2003; Ferraz and Finan 2008; McMillan and Zoido 2004; Stromberg 2004). For instance, Besley and Prat (2006) highlight the correlation between information accessibility, high incumbent turnover and low corruption thereby emphasizing that information to the electorate is an essential component of accountability. Besley and Case (1995) also acknowledge that yardstick competition possibly induces less shirking. Therefore, there is reason to believe that revealing information about their choices will affect the behavior of incumbent politicians in the experiment.

Studying trust in this context also complements recent work by Aimone and Houser (2013) who explore how institutions can take advantage of the benefits of betrayal aversion. On one hand, betrayal aversion can lead to costly punishment and a reluctance to trust; on the other, it has been shown to increase trustworthy behavior. They find that the option of discovering betrayal in a setting similar to Berg et al. (1995) significantly increases trustees' propensity to fulfill the expectations of investors. There is also work in behavioral economics showing that humans exhibit a desire for the good opinion of others as well as a good opinion of themselves. This explains why we observe trustworthy behavior even in situations where the trustor's reaction is unknown and retribution is not possible (Dana, Weber and Kuang 2007; Pelligra 2010); however, similar behavior might be explained by guilt aversion (Charness and Dufwenberg 2006).

The third and final hypothesis is: Hypothesis 3: Shirking (in magnitude and frequency) will decrease between treatments as voters are more informed. 
The next section details the experimental design and specifically defines transparency

and shirking in this context.

\section{EXPERIMENTAL DESIGN, PARAMETERS AND HYPOTHESES}

The experimental design features a novel voting game requiring detailed explanation. The first following subsection explains the design in detail, and it is followed by a section describing the parameters and procedures.

\subsection{Design}

I refer to subjects as either voters or candidates for the purposes of the paper, but context was not used in the experiment. The instructions can be found in the appendix. Subjects' roles remained fixed throughout the experiment. Candidates in any period were either incumbents or challengers. ${ }^{1}$ Incumbents actively represented a group of voters, called a district, and influenced the redistribution of wealth between districts. Their relative seniority among other incumbents affected the size of voters' monetary payoff as did an efficiency variable that could reduce voter payoffs. Senior incumbents also had the ability to take some of the voters' redistribution for themselves. Challengers in a particular period did not represent a district but were paid for performing an unrelated decoding task. They were randomly chosen to replace any incumbent who lost reelection. Voters, whose sole task was to vote on reelecting an incumbent, were grouped into districts of three voters, and each district had one incumbent politician.

There was a baseline condition and two treatments, and subjects only participated in one of them. In each experiment there were five paid practice periods that allowed subjects to understand the structure of the game and the functionality of an on-screen calculator. Districts voters and candidates were rerandomized before playing the final fifteen periods of the game.

\footnotetext{
${ }^{1}$ Candidates in the experiment were referred to as Type B players. Incumbents were referred to as being active, and challengers were referred to as being inactive.
} 
Subjects were aware of the number of periods and the particular information condition, which will be explained below. Subjects voluntarily completed an exit survey at the end of the experiment, for which they were paid. This survey asked questions about political participation, affiliation and trust. It is available upon request.

Each period of the experiment had two stages. In the first stage the incumbents made their choices, and in the second stage voters decided whether to reelect the incumbent based on the information they were given, which varied across treatment conditions.

Incumbents in Stage 1 voted on taxing the electorate, which received endowments each period. Each voter's entire endowment was allocated to a public account that was divided according to seniority if the incumbents passed the tax by majority rule. If an incumbent was senior, his voters received a positive share of the public account that was larger than their original endowment (subject to some commonly known measure of uncertainty and the incumbent's decision to keep some of the redistribution); otherwise, if the incumbent was junior, his voters contributed to the public account but received nothing in return. Senior incumbents indicated how much of the (pre-efficiency loss) transfer intended for their district would go to their personal account rather than the voters' accounts if the tax were to pass. If the tax did not pass, the subjects kept their endowments, no money was transferred and no shirking was possible. $^{2}$

Voters decided by majority rule whether to reelect the incumbent in Stage 2 of every period, and voters could not abstain from voting. They were aware of the allocation mechanism based on seniority as well as the relative seniority of all incumbents. Randomly selected and

\footnotetext{
${ }^{2}$ This was a major simplification but it made the incumbents' decisions more salient to voters and allowed them to understand that the asymmetric nature of the transfer. This component of the game is necessary for two reasons: 1) it reinforced the fact that voter payoffs were dependent on the actions of incumbents and 2) allowed senior incumbents the opportunity to actively buy the support of voters to allow for policy shirking.
} 
unidentifiable challengers replaced any incumbent who failed to win reelection, and losing incumbents became challengers. ${ }^{3}$ The experiment then advanced to the next period, which proceeded in the same manner. The following explains the differences across Stage 2 according to the information treatments in the order of increasing information.

No-Information Baseline (NI): Voters in the baseline treatment were never informed about the incumbent's choices or the realizations of the efficiency variable. They only saw their payoffs.

District-Information Treatment (DI): Voters in this treatment condition were informed about the variables that affected their payoff: the efficiency loss, and, if the incumbent was senior, how much of the transfer he directed to his own account.

All-Districts-Information Treatment (AI): This treatment condition differed from the DI treatment because voters in senior districts not only observed their own incumbent's shirking decision but the shirking (or lack thereof) of all senior incumbents. Incumbents remained unaware of the shirking of the others.

Candidates remained unidentifiable to voters throughout the experiment thereby eliminating any potential for voters to learn about the tendencies of particular candidates. Moreover, candidates could not see what other incumbents had chosen or their reelection results, thus minimizing the amount they could learn about particular districts' history or tolerance for shirking. Incumbents were randomly determined to be either "senior" or "junior" in the beginning period; thereafter, relative tenure measured by consecutive reelections and overall incumbent turnover determined seniority status in subsequent periods. This implies that an

\footnotetext{
3 This imitated the idea that a challenger's true preferences are not known to voters and can only be revealed over time (Chen and Niou 2005).
} 
incumbent's seniority status remained the same if no other incumbents left office. A junior incumbent could become senior if there was turnover among senior incumbents.

\subsection{Parameters}

In any session, there were $L$ candidates, $D$ districts, and $N_{d}$ voters in each district $d$. The values of these parameters was the same in every session: $L=10, D=5$, and $N_{d}=3$. This means that only five candidates were considered incumbents in any period. The top three incumbents in terms of tenure were considered senior. Twenty-five subjects total were needed per session. All payoffs were denominated in US dollars.

Voters received an endowment, $E$, each period $(\$ 0.45)$. The key variables include the tax on voters' endowments, $t$, the amount of money to be distributed from the public account, $\Pi$, the voters' shares of redistribution determined by incumbent seniority, $\sigma_{d}$, and the efficiency variable, $\alpha_{t}$. The tax was equal to the voters' entire endowment if it passed the legislature (i.e. $t=E)$; otherwise, it was zero. Thus, voter payoffs were as follows:

$$
U_{i d}=E-t+\alpha_{t}\left(\sigma_{d} \frac{\Pi}{N_{d}}-I\left\{s_{t}\right\} g_{d t}\right)
$$

where $\Pi=D * N_{d} * t$ since taxes were equal across all voters. The variable $\sigma_{d}$ determined the share of tax revenues a senior district received in any period. It was 0 for the voters of the junior incumbent and 1/3 for a senior incumbent. The efficiency variable $\alpha_{t}$ varied uniformly between $[1 / 3,1]$ each period. ${ }^{4}$ The lower bound of $1 / 3$ was chosen so that the ex-ante expected value of the transfer to senior district voters was $\$ 0.50$ such that (risk-neutral) senior district voters would

\footnotetext{
${ }^{4}$ The rational choice predictions related to this redistributive game setting, what political economists call the seniority-trap with zero incumbent turnover, holds whether the technology is positive, zero or negative sum (Buchanan and Congelton 1994). Ultimately, the fundamental incentives at work in the individual choice are 1) the expected difference between what a voter would get from redistribution and no redistribution and 2) the expected difference between what a voter would get from redistribution (allowing for shirking) and what a voter would get next period when electing the challenger. Neither of these depends on whether the net benefit of redistribution is positive, zero or negative.
} 
prefer that the tax passed, but it would still allow senior incumbents to disguise their actions in the NI treatment. The random draws of $\alpha_{t}$ were the same for each treatment and session. The incumbents did not know the value of $\alpha_{t}$ when making their decisions, but all subjects knew the distribution from which it was drawn. The term, $I\left\{s_{t}\right\} g_{d t}$, indicates the shirking decision of a senior incumbent where $I\left\{s_{t}\right\}$ is an indicator function of seniority and $g_{d t}$ is the amount of the redistribution that the incumbent from district $d$ directs to his own account from each voter. Thus, the expected value of $\alpha_{t} \times \sigma_{d} \frac{\Pi}{N_{d}}>E$ prior to the shirking decision of the incumbent. Voters in a senior district could receive as much as $\$ 0.75$ and as little as $\$ 0.25$ in any period with redistribution barring any shirking by the incumbent. Note that the incumbent could decide to keep the entire redistribution (i.e. $g_{d t}=\sigma_{d} \frac{\Pi}{N_{d}}$ ). Junior voters received nothing if wealth was redistributed. ${ }^{5}$

Incumbents received a wage, $W=\$ 0.60$ each period in office. Challengers earned money decoding text strings for $\$ 0.025$ for every correct code. They were not strictly limited in the number of codes they could submit in any round, but their time spent decoding was dependent on the time it took for the incumbents and voters to reach decisions. The rate of pay created incentive for incumbents to stay in office as well as kept challengers engaged throughout the experiment. ${ }^{6}$ Payoffs were summed across all periods. Table 1 summarizes the parameters of the design.

\footnotetext{
${ }^{5}$ A linear payoff function was implemented to sharpen incentives such that districts either desired a full tax or none at all. Thus the tax was a purely redistributive one. The structure of the shares implies that a majority of the active legislators always wanted to tax voters. Fixing the shares accordingly such that there is always an advantaged majority is also consistent with legislative bargaining literature where a minimum winning coalition decides how to split the pie (Baron and Ferejohn 1989, McKelvey and Riezman 1992, Frechette, Kagel and Lehrer 2003, Frechette, Kagel and Morelli 2009, Muthoo and Shepsle 2011).

${ }^{6}$ Skilled subjects averaged between 12 and 14 codes per period, leaving them with $\$ 0.30-0.35$ per period.
} 
Subjects were thoroughly instructed on the payoff structures and were told that the maximum amount an incumbent could take per voter was $\$ 0.75$ whereas the minimum was zero. The instructions intentionally separated incumbent and voter payoffs and referred to the former as having the ability to take a portion of the latter's payoff and adding it to their own account. Subjects' on-screen calculators allowed them to test different levels of efficiency as well as incumbent shirking before making their choices. The experimenter also walked them through arbitrary examples so they could gain proficiency using the calculator and understand its output.

\section{RESULTS}

Eight sessions were conducted at a large American public university. Subjects were recruited using the ORSEE online recruiting software (Greiner 2004). The experiment was programmed and conducted with the software z-Tree (Fischbacher 2007). The average payment was around \$18 including a \$10 participation payment for an hour in the lab. Instructions were read aloud and subjects went through five periods of practice before the treatment began. The aggregate results will follow the order of the hypotheses where both individual and collective results will be analyzed to understand trust. The amount taken from the voters' transfers by the incumbents will be referred to as their "take." First, note that voter endowments were redistributed virtually every period of each treatment. The incumbents in the NI, DI and AI treatments passed the tax $100 \%, 97 \%$ and $97 \%$ of the time respectively. All analysis is conditioned on redistribution occurring.

\subsection{Voting and Reelection}

The first set of results address accountability at the voter and district levels. I first tested Hypothesis 1 to understand how information affected accountability between treatments. I then 
explored Hypothesis 2 in order to understand within-treatment variation of accountability as shirking varied.

Before diving into the econometrics, I highlight the summary statistics in Table 2 where district mean reelection rates are used as independent observations to calculate the overall mean reelection rates in the different treatments. Likewise, I include the conditional means based on the seniority of the district's incumbent, whether a senior incumbent shirked or not, and whether the amount of shirking was greatest among all incumbents in a particular period. In general, there was some turnover in each treatment, but the overall reelection rates appear to be high (NI: 84\%, DI: $89 \%$, AI: $87 \%$ when the incumbent shirked). Note the reelection rates in the AI treatment. A significant difference in the average reelection rates of shirking and non-shirking incumbents is found using a Mann-Whitney test where the one-sided p-value is 0.01 . This suggests that accountability is comparison dependent where the average reelection rate of shirking incumbents was $87 \%$ compared to $100 \%$ for non-shirking incumbents. The difference is even greater when considering those incumbents who shirked the most. They were reelected $59 \%$ of the time on average (Mann-Whitney p-value 0.00). The other treatments did not see such significant differences.

I explore accountability using predicted probabilities of voting for the incumbent at the voter level and the predicted probabilities of reelection at the district level. Doing so allows us to see between-treatment and within-treatment effects over the range of incumbent shirking. The reelection probabilities are derived from treatment-specific logit models where the standard errors are clustered at the district level and the regressors include incumbent shirking measured in cents, the efficiency variable as an exogenous measure of voter payoffs, and voter trust measured by the exit survey. Subjects were asked several questions including, "How much of the 
time can you trust government to do the right thing?" Response choices included, "Never," "Only some of the time," "Most of the time," and "Just about always." These were coded from 14, meaning that a higher score indicated greater self-reported trust. The voter choice model uses the individuals' trust scores; whereas the district level model uses the average trust score of district voters.

The estimated model of voting for the incumbent is found in (2). The district reelection model is similar. A fuller description of the estimated models as well as a table of results can be found in the appendix.

$$
r_{i d t}=\beta_{1}+\beta_{2} \text { take }_{d t}+\beta_{3} \text { payoff }_{\text {idt }}+\beta_{2} \text { trust }_{i d t}+u_{d t}
$$

I compare the voter and district level results to identify effects on individual decision making and to see whether they manifest in the collective decision of the district. Figure 1 features the predicted probability of voting to reelect a senior incumbent across the range of possible shirking, all else held at the sample averages. The DI and AI treatments are each compared to the NI treatment in each of the respective panels. The dashed line in each panel indicates the predicted probability of reelection in the NI treatment baseline whereas the solid lines indicate the predicted probability in the respective treatments. The dotted lines indicate the $95 \%$ confidence intervals. ${ }^{7}$ Figure 2 shows similar results when controlling for an incumbent's shirking relative to the shirking of all senior incumbents. These are based on a similar logit model found in (2) with the addition of the ratio of an incumbent's shirking to the sum of all shirking i.e. an increasing value indicates an incumbent who shirked more relative to the other senior incumbents. Figure 3 features the predicted reelection probabilities at the district level.

\footnotetext{
${ }^{7}$ The NI treatment confidence intervals are withheld for clarity.
} 


\subsubsection{Accountability between treatments}

Comparing the DI and NI treatments and the AI and NI treatments in Figure 1 indicates between-treatment differences in predicted probability of voting for the incumbent at increasing amounts of shirking. At the maximum possible value of $\$ 0.75$ per voter, there was a $73 \%$ probability that a subject in the NI treatment would vote for the incumbent with a $95 \%$ confidence interval of $[51 \%, 93 \%]$. This probability is only $35 \%$ in the AI treatment with a $95 \%$ confidence interval of $[12 \%, 57 \%]$. This implies that voters respond to betrayal even when it is costly to do so; moreover, their response to betrayal is largely dependent on yardstick evaluations in terms of the relative amounts of shirking observed in the AI treatment. Note that the between-treatment difference between the DI and NI treatments is significant at only very high levels of shirking, which emphasizes the comparison dependence of accountability.

This yard-stick evaluation is further evident in Figure 2 where the horizontal axis measures the incumbents shirking as a ratio to all shirking by senior incumbents. This information is only known in the AI treatment, and it clearly affects voter choice. Voters were significantly less to vote for a shirking incumbent in the AI treatment when he did $50 \%$ or more of the shirking in a period.

Interestingly, these effects on voter behavior only manifest statistically at the district level in the AI treatment as shown in Figure 3. This is further evidence that accountability is comparison dependent. For instance, an incumbent who took the largest amount possible from voters was $65 \%$ likely to be reelected in the NI treatment with a $95 \%$ confidence interval of [31\%, 99\%], but only $21 \%$ likely to be reelected in the AI treatment with a $95 \%$ confidence interval of $[-6 \%, 48 \%]$. 
Result 1: There is a significant between-treatment difference in voting for a shirking incumbent between the AI and NI treatments based on predicted probabilities.

Result 2: There is a significant between-treatment difference in reelecting a shirking incumbent between the AI and NI treatment based on predicted probabilities.

\subsubsection{Accountability within treatments}

A voter is less likely to vote for an incumbent as taking increases when she has more information as shown in the DI and AI treatment results in Figure 1. The change in the DI treatment ranges from a 94\% likelihood of voting for the incumbent with a 95\% confidence interval of $[0.89,0.98]$ when the incumbent does not shirk to a $38 \%$ likelihood with a $95 \%$ confidence interval of $[0.17,0.59]$ when the incumbent takes the largest amount possible. The likelihood varies within the AI treatment from $88 \%$ with a $95 \%$ confidence interval of [0.81, $0.98]$ to a $35 \%$ likelihood with a $95 \%$ confidence interval of $[0.13,0.57]$ over the same range of shirking.

Results indicate that reelection is not predicted to decrease as shirking increases in the NI treatment; however, there are within-treatment effects in the DI and AI treatments where incumbents are significantly less likely to be rewarded with reelection the more they take from voters. Once again, the within-treatment effect in the DI treatment is only significant at very high amounts of taking. 
Result 3: There are within-treatment decreases in the predicted probability of voting for an incumbent as shirking increases in the DI and AI treatments.

Result 4: The predicted probabilities of reelection in the DI and AI treatments indicate withintreatment decreases as shirking increases.

\subsection{Shirking}

Table 3 displays the mean incumbent take and frequency across the different conditions. The averages of each subject incumbent from each treatment are treated as independent observations. Recall that the incumbents could not see how much shirking was occurring in other districts, which simplifies the analysis. Analysis of the frequency of taking a positive amount (out of a possible fourteen periods) indicates there are significant differences between treatments. Specifically, incumbents shirked significantly less frequently in the AI treatment compared to the NI treatment, or $32 \%$ of the time versus $61 \%$ of the time with a Mann-Whitney p-value of 0.04 . Interestingly, differences in the magnitude of shirking between treatments are not statistically different as is indicated by the p-values from Mann-Whitney tests comparing the average amount taking measured in cents (Between-treatment Mann-Whitney p-values: NI - DI: 0.40; NI - AI: 0.56; DI - AI: 0.23). Therefore, incumbents adjusted how often they shirked in response to an informed electorate, but they did not adjust how much they shirked when they did take from voters.

Result 5: Information in the AI treatment decreased the frequency of shirking, but the magnitude of incumbents' shirking was not significantly affected. 


\section{DISCUSSION}

The results indicate that even in a collective action setting where accountability for trust betrayal is costly, voters (namely the principals) respond to betrayal when they can distinguish the actions and intentions of the incumbent (namely the agent) from the impact of nature on their payoff; however, the response is largely comparison dependent.

It is important to consider the cost of holding incumbents accountable for trust betrayal. The average wait for seniority (i.e. a recently elected junior challenger moving up to senior status) after voting out a senior incumbent was 4.56 periods ( $n=18$; st.dev. 3.55$)$ with the maximum being eleven and the minimum being one period. This means that the voters gave up approximately $\$ 1.87$ on average when electing a challenger over a senior incumbent. ${ }^{8}$ If we take $\$ 0.09$ per period as the average loss per voter in a senior district, where the ex-ante expected payoff is $\$ 0.50$ per period $(75 \times 2 / 3)$ and the ex-post expected payoff is $\$ 0.41$ per period $((75$ $13.56) \times 2 / 3$ ), voters lost only $\$ 0.41$ on average over those 4.56 periods by keeping the incumbent. Thus, replacing a shirking incumbent cost voters on average 4.5 times what they would have lost by tolerating trust betrayal. ${ }^{9}$

From a policy perspective, improving information access to voters is not only important for motivating voters but for affecting incumbent behavior. Incumbent behavior in this

\footnotetext{
${ }^{8}$ These totals were calculated using the average amount taken by incumbents across all treatments (13.56 cents) and the expected transfer efficiency (2/3) and the average number of periods of seniority given up. So voters that achieved seniority a second time lost on average $(75-13.56) \times(2 / 3) \times(4.56)=\$ 1.87$. The voters who kicked a senior incumbent out of office and never achieved seniority status again averaged 6.5 periods $(\mathrm{n}=8$; st.dev. 3.66) between the election of a junior challenger and the end of the game. These voters gave up $(75-13.56) \times(2 / 3) \times(6.5)=\$ 2.66$ on average.

${ }^{9}$ The majority voting process means that the individual voter is not sacrificing other voters' payoffs when responding to betrayal without the consent of at least one other player, thereby mitigating any property right concerns.
} 
experiment is possibly explained by trust-responsiveness where trusting behavior engenders a trustworthy response on the part of the agent even in the face of large opportunity costs (Guerra and Zizzo 2004; Pelligra 2010). Likewise, incumbents may be displaying guilt aversion based on what they believe are voters' payoff expectations (Charness and Dufwenberg 2006). Future research could attempt to distance the voters and elected officials within the experiment. For instance, an actual legislator partaking in patronage may not feel he is violating his constituents' trust if he is providing sufficiently large benefits along other policy or spending dimensions - i.e. a bread and circuses argument. Likewise, he can psychologically and publicly defend his decisions as being good for the group, as is often done when elected officials are on fact finding trips to Italy or improving roads near their property in their hometown (see Fallis, Higham, and Kindy 2012; Higham, Kindy and Fallis 2012). Overall, the results point to the limitations of policy implications involving information. Future research should address alternatives to seniority within legislatures and other checks on incumbent shirking such as demotion within parties, all of which could be explored using experiments.

Finally, I link this work with the existing survey work on political trust by looking more closely at subjects' self-reported trust in government. Recall that subjects voluntarily completed a survey following the experiment. Parker (1989) and Parker and Parker (1993) find that selfreported trust predicts vote choice where distrust tends to stem from events like scandal, broken promises, and war (Levi and Stoker 2000). An analysis of the self-reported trust indicates that low trusting subjects are significantly less likely to vote for shirking incumbents than those who report a high level of political trust. Figure 4 displays subjects' average predicted probability of voting for the incumbent compared across self-reported political trust where trust decreases along the horizontal axis. This basic result is intuitive and consistent with other survey research 
in that distrust negatively affects how voters evaluate incumbents' performance. This also helps to argue that the behavioral results found in this study are related to trust and the betrayal of trust rather than strict fairness concerns like inequality aversion.

\section{CONCLUSION}

The featured experiment places subjects in the roles of voters and candidates, where the latter have an opportunity to benefit themselves at the cost of voters while in office. The treatments vary the feedback voters receive where in the baseline No Information treatment voters only see their payoffs and cannot easily infer the intentions of incumbents. The voters in the District-Information treatment know whether their payoff was a result of uncertain efficiency or shirking. Finally, voters in the All-Districts-Information treatment can compare the actions of their own incumbent to that of others.

Providing feedback about relative incumbent behavior in the All-Districts-Information treatment significantly lowered the tolerance for shirking compared to the baseline. Not only were voters less likely to vote for a shirking incumbent, predicted reelection rates indicate a lower likelihood of shirking incumbents returning to office, which emphasizes the importance of comparison dependence in evaluating agents. Moreover, these effects were larger at greater amounts of shirking. Thus, the elements of trust and expectations of fair treatment encourage accountability even when it is costly but rely on relative comparisons of trustworthy behavior.

Information helped overcome the principal-agent problem by discouraging incumbent shirking. Incumbents were less likely to shirk when information about the incumbent's choice was given to voters. This suggests that feedback to voters is just as important in inducing selfregulation among incumbents as it is in inducing accountability through elections. 
Table 1: Experimental parameters

Number of Sessions

Number of Subjects

Voters per District $\left(N_{d}\right)$

Total Voters per session

Total Candidates per session

Total subjects per session

Voter endowment: $E$

Tax (if passed): $t$

Incumbent wage: $W$

District share of redistribution: $\sigma_{d}$

Expected value of transfer:

$\alpha_{t} \times \sigma_{d} \frac{\Pi}{N_{d}}\left(\right.$ when $\left.g_{d t}=0\right)$
6 (two per treatment)

150 (90 voters, 60 candidates)

3

15

10

25

$\$ 0.45$ per period

$\$ 0.45$ per period

$\$ 0.60$ per period

$1 / 3$ if senior; 0 if junior

$\$ 0.50$ per period 
Table 2: Reelection rates at the district level

\begin{tabular}{ccccc}
\hline \multirow{2}{*}{ Treatment } & Take Max & Senior & Take $>0$ & Junior \\
\hline \multirow{3}{*}{ NI } & 0.72 & 0.84 & 1.00 & 0.51 \\
& $(0.13)$ & $(0.07)$ & $\cdot$ & $(0.16)$ \\
& $\mathrm{N}=4$ & $\mathrm{~N}=7$ & $\mathrm{~N}=2$ & $\mathrm{~N}=6$ \\
DI & 0.92 & 0.89 & 0.98 & 0.55 \\
& $(0.06)$ & $(0.06)$ & $(0.02)$ & $(0.14)$ \\
& $\mathrm{N}=5$ & $\mathrm{~N}=9$ & $\mathrm{~N}=7$ & $\mathrm{~N}=8$ \\
AI & 0.59 & 0.87 & 1.00 & 0.63 \\
& $(0.13)$ & $(0.04)$ & $\cdot$ & $(0.12)$ \\
& $\mathrm{N}=8$ & $\mathrm{~N}=9$ & $\mathrm{~N}=6$ & $\mathrm{~N}=9$ \\
\hline \hline
\end{tabular}

District averages used as independent observations. Between treatment Mann-Whitney p-values for Take Max: (one-sided) NI-DI: 0.08; NI-AI: 0.22; DI-AI: 0.05. Between treatment MannWhitney p-values for Take>0 : (one-sided) NI-DI: 0.78; NI-AI: 0.45; DI-AI: 0.22. Within treatment (Take > $0 \mathrm{v}$. Take $=0$ ) Mann-Whitney p-values: (one-sided) NI: 0.06; DI: 0.11; AI: 0.01 .

Table 3: Average Take

\begin{tabular}{ccccc}
\hline Treatment & Freq. Take $>0$ & $\begin{array}{c}\text { Mann-Whitney } \\
\text { P-Value }\end{array}$ & Average Take & $\begin{array}{c}\text { Mann-Whitney } \\
\text { P-value }\end{array}$ \\
\hline \multirow{2}{*}{ NI } & 0.61 & NI - DI: 0.14 & 14.59 & NI - DI: 0.40 \\
& $(0.15)$ & NI - AI: 0.04 & $(6.08)$ & NI - AI: 0.56 \\
NI & 0.39 & & 11.77 & \\
& $(0.12)$ & DI - AI: 0.32 & $(5.41)$ & DI - AI: 0.23 \\
& $\mathrm{~N}=10$ & & $\mathrm{~N}=10$ & \\
AI & 0.32 & & 15.64 & \\
& $(0.08)$ & & $(5.19)$ & \\
\hline
\end{tabular}

Subject incumbent averages used as independent observations. 
DI

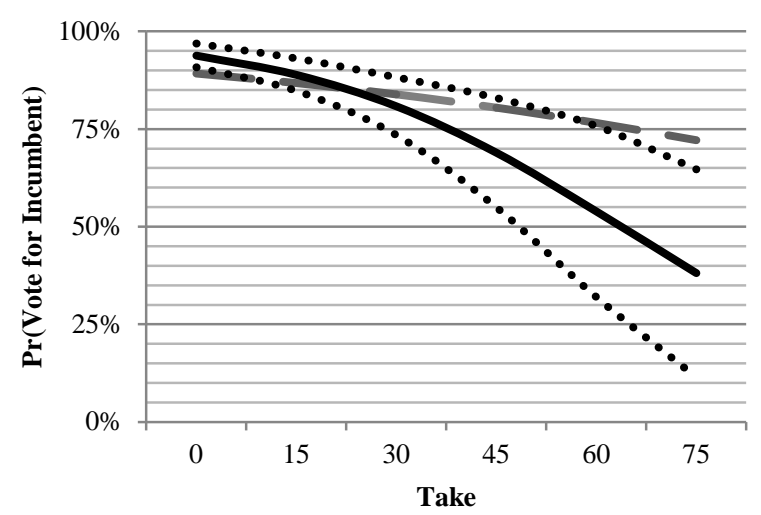

AI

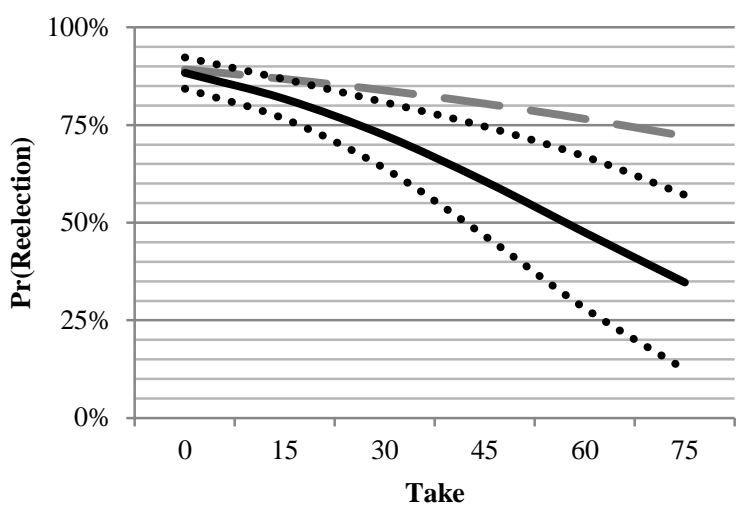

Fig. 1 Predicted probabilities of voting for the incumbent over the range of taking by treatment. The dashed lines indicate the predicted probability from the NI treatment. The solid lines indicate the predicted probabilities from each of the respective treatments. The dotted lines indicate the $95 \%$ confidence intervals.

DI

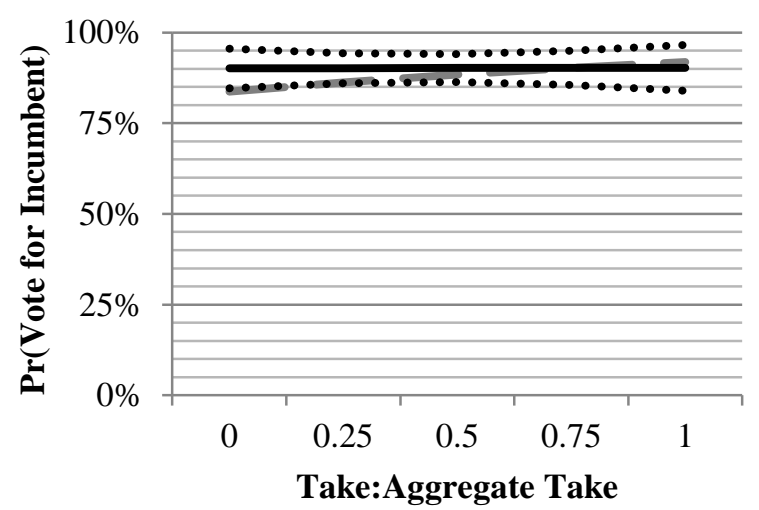

AI

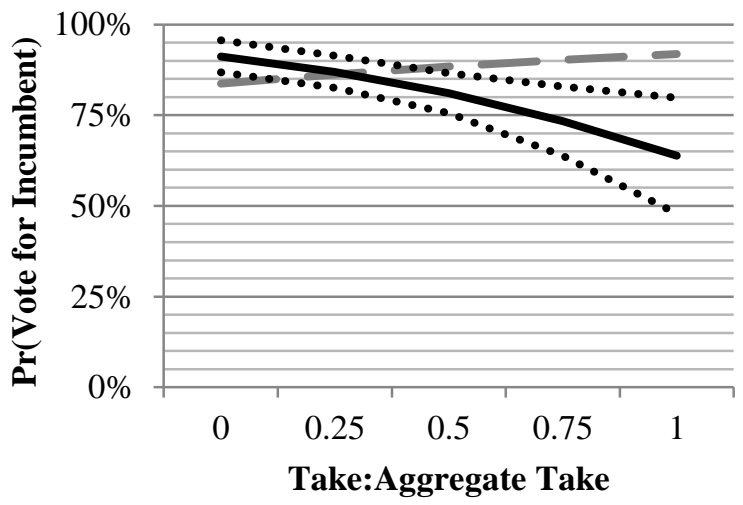

Fig. 2 Predicted probabilities of voting for the incumbent over the range of the incumbent's take to the sum of all taking by treatment. The dashed lines indicate the predicted probability from the NI treatment. The solid lines indicate the predicted probabilities from each of the respective treatments. The dotted lines indicate the $95 \%$ confidence intervals. 
DI

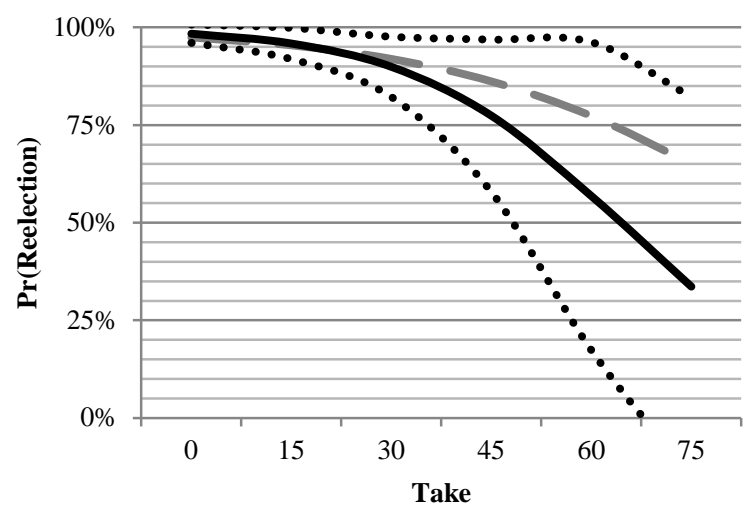

AI

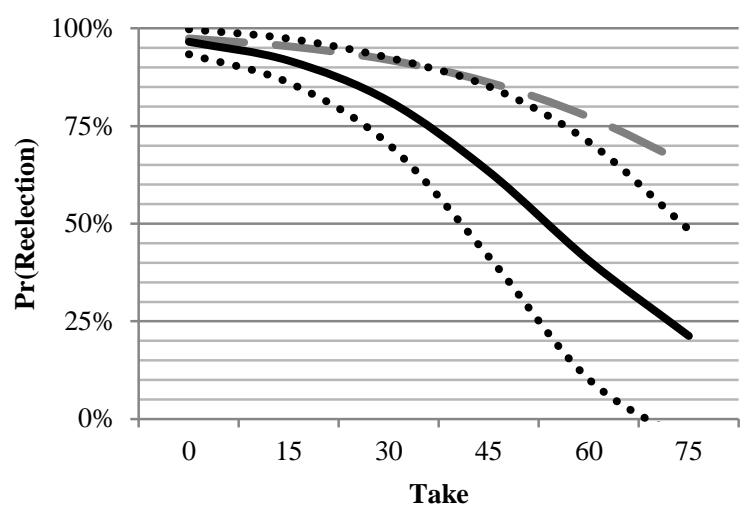

Fig. 3 Predicted probability of winning reelection over the range of taking by treatment. The dashed lines indicate the mean predicted probability of reelection from the NI treatment. The solid lines indicate the respective predicted probabilities from each treatment. The dotted lines indicate the $95 \%$ confidence intervals.

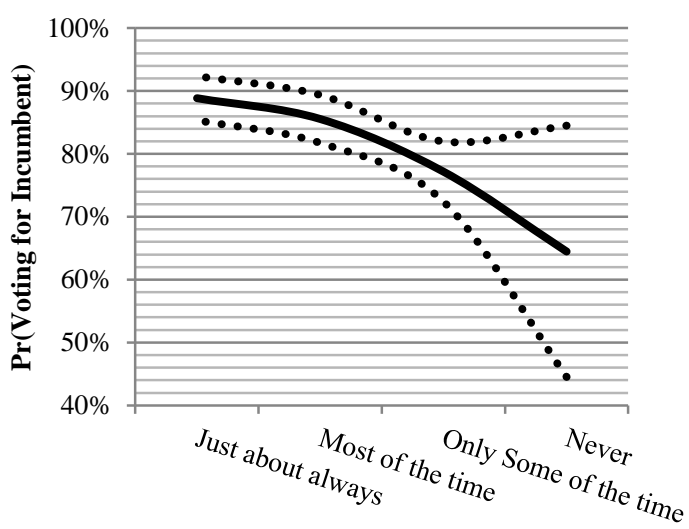

Fig. 4 Predicted probability of voting for the incumbent and self-reported trust. The dotted lines indicate the $95 \%$ confidence interval. 


\section{References}

Abbink, K., Irlenbusch, B., \& Renner, E. (2000). The moonlighting game: An experimental study on reciprocity and retribution. Journal of Economc Behavior and Organization, 265-277.

Aimone, J. A., \& Houser, D. (2012). What you don't know won't hurt you: a laboratory analysis of betrayal aversion. Experimental Economics, 15(4), 571-588.

Aimone, J. A., \& Houser, D. (2013). Harnessing the benefits of betrayal aversion. Journal of Economic Behavior \& Organization, 89, 1-8.

Alm, J., G. H. McClelland and W.D. Schulze. (1992). "Why do people pay taxes?" Journal of Public Economics 48:21-38.

Baron, David P. and John A. Ferejohn. 1989. "Bargaining in Legislatures," The American Political Science Review 83: 1181-1206.

Bernhardt, Dan, Sangita Dubey and Eric Hughson. 2004. "Term Limits and Pork Barrel Politics,” Journal of Public Economics 88: 2383-2422.

Berg, J., Dickhaut, J., \& McCabe, K. (1995). Trust, reciprocity and social history. Games and Economic Behavior, 122-142.

Besley Timothy and Robin S. L. Burgess. 2002. "The Political Economy of Government Responsiveness: Theory and Evidence from India." Quarterly Journal of Economics 117: 14151451.

Besley, Timothy and Anne Case. 1995. "Incumbent behavior: Vote-seeking, tax-setting, and yardstick competition." The American Economic Review 85: 25-45.

Besley, Timothy and Andrea Prat. 2006. "Handcuffs for the Grabbing Hand? Media Capture and Government Accountability." The American Economic Review 96: 720-736.

Buchanan, James M., and Roger D. Congleton. 1994. "The incumbency dilemma and rent extraction by legislators." Public Choice 79: 47-60.

Camerer, Colin. 2003. Behavioral Game Theory. Princeton: Princeton University Press.

Chari, Varadarajan V., Larry E. Jones, and Ramon Marimon. 1997. "The Economics of Splitticket Voting in Representative Democracies." The American Economic Review 957-976.

Charness, G., \& Dufwenberg, M. (2006). Promises and partnership. Econometrica, 74(6), 15791601.

Chen, Kong-Pin, and Emerson M.S. Niou. 2005. "Term Limits as a Response to Incumbency Advantage,” The Journal of Politics 67: 390-406. 
Dana, J., Weber, R. A., \& Kuang, J. X. (2007). Exploiting moral wiggle room: experiments demonstrating an illusory preference for fairness. Economic Theory, 67-80.

Djankov, Simeon, Caralee McLiesh, Tatiana Nenova, and Andrei Shleifer. 2003. "Who Owns the Media?" Journal of Law and Economics 46: 341-381.

Dick, A. R., \& Lott Jr, J. R. (1993). Reconciling voters' behavior with legislative term limits. Journal of Public Economics, 50(1), 1-14.

Fallis, David S., Scott Higham and Kimberly Kindy. 2012. "Congressional earmarks sometimes used to fund projects near lawmakers' properties," The Washington Post, February 7. Accessed February 7, 2012. http://www.washingtonpost.com/investigations/congressional-earmarkssometimes-used-to-fund-projects-near-lawmakersproperties/2012/01/12/gIQA97HGvQ_story.html

Falk, A., Fehr, E., \& Fischbacher, U. (2008). Testing theories of fairness - Intentions matter. Games and Economic Behavior, 62, 287-303.

Ferraz, Claudio and Frederico Finan. 2008. "Exposing Corrupt Politicians: The Effects of Brazil's Publicly Released Audits on Electoral Outcomes," Quarterly Journal of Economics 123: 703-745.

Finkel, E. J., Rusbult, C. E., Kumashiro, M., \& Hannon, P. A. (2002). Dealing with betrayal in close relationships: Does commitment promote forgiveness?.Journal of personality and social psychology, 82(6), 956.

Fischbacher, Urs. 2007. "Z-Tree: Zurich Toolbox for Ready-made Economic Experiments," Experimental Economics 10(2): 171-178.

Feld, L. P., \& Frey, B. S. (2002). Trust breeds trust: How taxpayers are treated.Economics of Governance, 3(2), 87-99.

Guerra, G., \& Zizzo, D. J. (2004). “Trust responsiveness and beliefs," Journal of Economic Behavior and Organization, 25-30.

Hetherington, Marc J. (1999). "The effect of political trust on the presidential vote, 1968-96," American Political Science Review 93: 311-326.

Higham, Scott, Kimberly Kindy and David S. Fallis. 2012. "Capitol Assets: Some legislators send millions to groups connected to their relatives," The Washington Post, February 7. Accessed February 7, 2012. http://www.washingtonpost.com/politics/congress/capitol-assetssome-legislators-send-millions-to-groups-connected-to-theirrelatives/2012/01/10/gIQAyrzdxQ_story.html 
Holcombe, Randall G. 1989. "A note on Seniority and Political Competition," Public Choice 61: 285-288.

Karp, J.A. (1995). “Explaining public support for legislative term limits,” Public Opinion Quarterly 59:373-391.

Keele, Luke. (2007). "Social Capital and the Dynamics of Trust in Government," American Journal of Political Science 51: 241-254.

Koehler, J. J., \& Gershoff, A. D. (2003). "Betrayal aversion: When agents of protection become agents of harm," Organizational Behavior and Human Decision Processes, 244-261.

Levi, M., \& Stoker, L. (2000). Political trust and trustworthiness. Annual Review of Political Science, 3(1), 475-507.

Listhaug, O. (1995). "The dynamics of trust in politicians," In Citizens and the State, ed. H. Klingemann, D. Fuchs. pp. 261-297. New York: Oxford Univ. Press

McCabe, K. A., Rigdon, M. L., \& Smith, V. L. (2003). Positive reciprocity and intentions in trust games. Journal of Economic Behavior and Organization, 52(2), 267-275.

McKelvey, Richard D. and Raymond Riezman. 1992. "Seniority in Legislatures," The American Political Science Review 86: 951-965.

McMillan, John and Pablo Zoido. 2004. "How to Subvert Democracy: Montesinos in Peru," The Journal of Economic Perspectives 18: 69-92.

Ostrom, E., \& Walker, J. (2002). Trust and Reciprocity: Interdisciplinary Lessons for Experimental Research. New York: Russell Sage.

Parker, Glenn R. (1989). "The role of constituent trust in congressional elections," Public Opinion Quarterly 53: 175-196.

Parker, Suzanne L. and Glen R. Parker. (1993). "Why do we trust our Congressman?” The Journal of Politics 55: 442-453.

Pelligra, V. (2010). Trust responsiveness. On the dynamics of fiduciary interactions. The Journal of Socio-Economics, 653-660.

Rigdon, M. L., McCabe, K. A., \& Smith, V. L. (2007). "Sustaining cooperation in trust games." The Economic Journal, 117(522), 991-1007.

Sigelman L., Sigelman C.K., and Walkosz B.J. (1992). "The public and the paradox of leadership: an experimental analysis," American Journal of Political Science 36: 366-385. 
Strömberg, David. 2004. “Radio's Impact on Public Spending," Quarterly Journal of Economics 119: 189-221.

Weingast, Barry R. and William J. Marshall. 1988. "The Industrial Organization of Congress; or, Why Legislatures, Like Firms, Are Not Organized as Markets," The Journal of Political Economy 96: 132-163. 


\section{Acknowledgments}

I gratefully acknowledge financial support from the National Science Foundation (027354), the Economic Science Institute at Chapman University and John and Hallie Quinn. I thank Jared P. Barton, David J. Cooper, E. Glenn Dutcher, Jens Grosser, Randall G. Holcombe, R. Mark Isaac, David Rojo Arjona, John B. Ryan, Timothy C. Salmon, Andrew Smyth, Bart J. Wilson and other members of the Experimental Social Science Group at Florida State (XS/FS) and the Economic Science Institute at Chapman University for their comments and insight. I also thank the three anonymous referees and editor whose efforts and suggestions are greatly appreciated. 